\title{
One hundred years ago
}

\section{The certifying of lunatics}

SIRS, - We should be glad if you could inform us whether it is the usual practice for the Poor-law district medical officer to certify all pauper lunatics in his district irrespective of the fact that they are being professionally attended by their own private practitioner. In this district when we have a case to be certified we inform the relieving officer of the fact and the matter then passes out of our hands. The Poor-law medical officer is called in and he signs the necessary papers and pockets the fee. We believe that in many districts the relieving officer requests the attending practitioner to sign the certificate and arranges the interview with the magistrate, \&c. The point we wish to get at is whether it is probable that the guardians instruct their relieving officer to call in their own medical officer in every case, or whether it is likely to be a private arrangement between the relieving officer and the medical officer. If the latter be the case it is obviously unfair to the other men and the matter should be rectified without delay.

We are, Sirs, yours faithfully, Sept. 20th, $1902 \quad$ FAIRPLAY \& Co.

$*$ The Poor-law district medical officer is often, on appointment by the guardians, told that it is one of his regular duties to certify pauper lunatics, although in some districts the relieving officer requests the attending practitioner to sign the certificate. The relieving officer usually follows some general instruction from the guardians as to the medical officer who should be asked to sign the certificates. Anything like a private arrangement between the relieving officer and the particular medical officer is wrong and might easily make both parties liable to prosecution. The recent scandals connected with certain Poor-law unions in which the relieving officers had received payments from proprietors of private asylums in connexion with the certifying of lunatics will be fresh in the memory of our readers. - ED. L.

\section{REFERENCE}

Lancet, 4 October 1902, 960

Researched by Henry Rollin, Emeritus Consultant Psychiatrist, Horton Hospital, Epsom, Surrey. 